\title{
A ANALOGIA E O PRINCÍPIO DE INDIVIDUALIZAÇÃO EM MATÉRIA PENAL
}

\author{
JOSE' SALGADO MARTINS \\ Catedrático de Direito Penal.
}

Tema dos mais difíceis é o que concerne ao papel da analogia na aplicação das normas que compõem o complexo jurídico-penal.

Diante da omissão da lei, pertinente à espécie concreta, o aplicador procura, guiado pelo raciocínio analógico, encontrar disposição disciplinadora de hipóteses semelhantes àquela espécie; e assim amplia o âmbito da norma, fazendo-a abranger o caso não previsto.

A analogia não é um simples processo de interpretação da lei, mas um processo de integração do sistema legal.

Parece-nos que assiste razão a LUíS JIMÉNEZ DE ASÚA, (1), quando distingue: "A analogia sempre conduz a uma extensão da lei, distingue-se, porém, da interpretação extensiva, porque nesta, ainda que o intérprete se sirva do elemento sistemático, o caso está previsto pelo legislador, que teria empregado expressões inadequadas, enquanto que, na aplicação analógica, não foi pela lei contemplada a hipótese. Por isso - continua o eminente penalista espanhol - não se deve falar de interpretação analógica, ou melhor esta é cousa distinta da analogia, porque a interpretação é o descobrimento da vontade da lei em seus próprios textos, enquanto que com a analogia não se interpreta uma disposição legal, que em absoluto falta, mas, pelo contrário, se aplica ao caso concreto uma regra que disciplina um caso semelhante. $\mathrm{Na}$ interpretação extensiva falta a expressão literal,

* - Conferência proferida na sessão de encerramento do último Congresso (1) - La mề de junho de 1957. 
mas não falta a vontade da lei; na analogia falta também a vontade desta (2)".

Nesse caso, quando se fala em aplicação analógica da lei, estamos a supor uma lacuna na lei que será preenchida pela extensão de dispositivos componentes do sistema, a casos que refugiram à previsão do legislador.

Para outros autores, (3) no entanto, a analogia é processo interpretativo, através do qual se procura extrair do núcleo mesmo da norma e como decorrência da razão que o informa, a regra que o legislador não quís ou não soube expressar.

Entre nós, o eminente Ministro NELSON HUNGRIA, (4) cuja contribuição ao Direito Penal brasileiro se destaca de maneira ímpar, entende que a analogia não é interpretação, mas criação ou formação de direito novo, isto é, aplicação extensiva da lei a casos de que esta não cogita. " $E$ ' um processo integrativo, e não interpretativo da lei". "Costuma-se distinguir entre analogia legal (analogia legis) e analogia jurídica (analogia juris), conforme seja seu ponto de partida um singular preceito de lei ou os princípios gerais (fundamentais) de direito; mas tal distinção é, de todo, indiferente ao Direito Penal, que repele, de modo geral (e não apenas no que concerne a incriminações ou sanções), "Thbas as formas de analogia". E exemplifica o eminente mestre: "Tome-se, para exemplo de inextensibilidade por analogia, o artigo 198 do Código Penal, que incrimina, como atentado à liberdade de trabalho, o fato de "constranger alguém, mediante violência ou grave ameaça, a celebrar contrato de trabalho", deixando de contemplar a hipótese de constrangimento para não celebrar dito contrato, apesar da completa identidade de razão para inclúi-la no mesmo praeceptum". "A hipótese omitida não pode ser enquadrada no referido artigo 198 (embora seja punível a outro título). "Outro exemplo: tendo o Código omitido entre os crimina falsi a "guarda" de estampilhas falsas, não pode ser aplicado no caso, por paridade, o art. $289, \S 1^{\circ}$, que incrimina a "guarda" de moeda falsa. Se o fato não representa, in concreto, co-autoria em crime de falsificação de estampilhas, ou receptação, ou favorecimento real, terá de ficar impune".

A seguir, NELSON HUNGRIA, (5) coerente com a opinião expendida, distingue entre analogia e interpretação analógica que afirma ser permitida pela própria lei. Trata-se, aqui, diz o insigne jurista, de analogia intra legem, de que é exemplo, entre outros

(2) - Alude L. JIMENEZ DE ASÚA que a expressão interpretatio analogica remonta a JOAQUIM HOPPER, De Juris Arte, Lovaina, 1553 Trat de Derecho Penal, B. Aires, 1950, tomo II, pág. 418.
(3) - NORBERTO BOBBIO, L'Analogia e il Diritto Penale, in Rev. Pen. 1938, (5) - Comentáriós á có Código Penal, Rio, 1949, vol. I, pág. 73 muitos, a consentida na fórmula do crime continuado (art. 51, $\S 2^{\circ}$, do Cód. Penal), que, depois de mencionar as condições de "tempo lugar, maneira de execução", indiciárias da homogeneidade objetiva dos fatos sucessivos, acrescenta: "e outras semelhantes". E' óbvio que, no limite da semelhança referida à casuística exemplificativa, cabe ao juíz reconhecer as hipóteses não previstas individualmente".

Já neste início de exposição do intrincado tema, queremos sublinhar as nossas divergências com o exímio penalista, deixando para fundamentá-las depois.

Para nós a denominada interpretação analógica é também uma forma de integração do sistema legal. $O$ que ocorre é que o legislador, às vêzes, foi intencionalmente omisso, porque, atenta a complexidade das circunstâncias que se podem constituir imprevistamente, não quís descer aos excessos do casuísmo, preferindo ficar numa fórmula genérica. Sabe êle muito bem que outras hipóteses poderão configurar-se na realidade da vida e deixou ao aplicador da lei penal o encargo de descobrir as relaçôes que elas, por ventura, possam guardar com a previsão legal. (6)

Outra discrepância entre o nosso pensamento e o de NELSON HUNGRIA concerne à proscrição absoluta da analogia do campo penal.

Apenas bosquejados alguns aspectos fundamentais da temática da analogia, cabe agora situar o problema na doutrina.

A analogia se entrelaça íntima e profundamente com o problema da interpretação e com o problema das fontes do Direito Penal. (7)

Basta referir essas correlações para que se compreendam as dificuldades da matéria que deita raízes no vasto campo da filosofia jurídica.

Mas ainda a analogia apresenta profundas implicações com o princípio nullum crimen sine lege, o denominado princípio de reserva ou de legalidade do delito, cuja versátil fortuna política apresenta na história do direito penal um movimento verdadeiramente pendular.

Nos momentos de arbítrio e de opressão, quando as conveniências e as secretas razões de Estado não querem deter-se diante das liberdades fundamentais do homem, o princípio é negado, como ranço de velhas doutrinas incompatíveis com a vida criadora

(6) - G. MAGGIORE alude a lacunas intencionais e a lacunas involuntárias (7) - ERNESTO ZITELMANN, no ensaio publicado em 1902, sob o título Lücken in Recht, (As lacunas no Direito), compreendeu a transcendência da indagaçấ, escrevendo: «Penetra-se com ela, sem duvida alguma, no mais dntre coacão e liberdade, entre direito positivo e direito natural
Ciência del Derecho, editorial Losada, B. Aires, 1949, pág. 290). 
do Direito. Mas, quando o bom senso volta a orientar as construções jurídicas perduráveis, o reconhecimento do princípio é o signo da própria normatividade penal, a cuja sombra a liberdade da pessoa é resguardada às incursões do autoritarismo estatal.

A história recente e a história atual atestam-no.

No Código penal soviético, o emprêgo da analogia, mesm? para incriminar, desconhece o princípio. $E$, no direito penal da Alemanha hitlerista. a lei é o que o Führer ordena, como proclamava SCHAFFSTEIN (8) do alto de sua cátedra em Leipzig. E na crônica do tribunal de Nüremberg existe a mácula de cond'enações em que se desprezou o princípio nullum crimen sine lege. Para a glória do Direito Penal democrático, o protesto de Donnedieu des Vabres foi alentadora advertência.

O princípio volta a ser proclamado, como o fôra pela Revolucão Francesa, entre os direitos fundamentais do homem, pela Assembléia Geral das Nações Unidas (9).

Referindo-se à formulação atual do princípio nullum crimen sine lege, em brilhante ensaio, aparecido no seu recente livro $F$ en el Derecho (10), o eminente penalista argentino SEBASTIÁN SOLER pergunta se é correto pressupor que na atualidade, em pleno século XX, o princípio nullum crimen deva ser formulado exatamente o mesmo como o fôra nos fins do século XVIII? Ou se não é possível acrescentar "un nuevo aporte enriquecedor del viejo principio"?

Pensa, então, SOLER que a doutrina do delito-tipo, formulada por BELING e desenvolvida por tôda uma corrente de pena listas, na Alemanha e na Itália, e atualmente incorporada como doutrina pacífica ao Direito Penal até que outras concepcões possam substituíla, constitui, por assim dizer, o novo clima doutrinário dentro do qual o princípio assume perspectivas mais ricas. Explica SOLER: "A conduta de um sujeito apresenta sempre a forma de uma corrente sem soluções de continuidade; é o desdobramento exterior da personalidade no tempo. $O$ delitual esta dentro dessa corrente heraclideana, nesse pertétuo vir-a-ser, porém não pode ser definido como puro vir-a-ser, porque isso importaria a possibilidade de considerar delituoso qualquer momento ou a totalidade do momento, e o delito viria a ser, então, uma qualidade pessoal do sujeito e não uma simples acão".

"Dentro da vida prática - e o direito pertence a êsse plano (8) - O princípio nullum crimen, nulla poena sine lege figura atualmente como
direito fundamental, no art. 103 da Const. da Rep. Federal Alemân (V.
estudo da ADOLFO SCHÖNKE, Interpretazione, analogia e consuetudine nel diritto penale, in Riv. Italiana di Dir. Penale, ano 1949 , no 5 , pág. 511; HANS WELzEL, Derecho Penal, B. Aires, 1956, pág. 26.

(10) - Declaracãa Universal dos Direitos Humanos, art. XI, n. 2 .
- mediante palavras efetuamos cortes, às vêzes bastante arbitrários, no curso indiferenciado dêsse fluir. Selecionamos algumas tras, únicas que interessam para determinado fim, e com elas, notas, as unicas que intertsimos um nome. Esse nome com o sòmente com elas, constituimos um nome. Esse nome com o qual selecion dizemos: João pinta, ainda que, na rea lidade nesse mesmo momento, êle realize muitas outras cousas, algumas das quais são compreendidas pelo verbo, sem ser pròpriamente pintar: molhar os pinceis, preparar uma côr, situar um modêlo, e outras cousas das quais nos desinteressamos, não obsmodêlo, e outras sentado, olhar, quedar tante a sua apresentação simulânea: esta quando se, fumar, etc. Do mesmo modo quando João escreve ou quando rouba. Mediante o emprego de um verbo produzimos uma seleção de notas e criamos uma solução de continuidade. Se o delito ação, toda figura delituosa deve encerrar-se num verbo. Neste ação, delito não é conduta, não é ação em sentido senão uma ação determinada. Tão acentuada é essa exigeral, senão uma ação determinada. Tá delituosas costumam não gência de determinação que as figuras delituosas costumam náo consistir simplesmente em um verbo: geralmente a própria ação enunciada pelo verbo está limitada por numerosos complementos. enunciada pelo verbo civilizado deve estar constituído, pois, por uma série limitada de definicões cerradas de ação. Essa estrutura do direito penal nos permitiu - acrescenta SOLER - definí-lo como direito penal nos permitiu - acrescenta $\mathrm{O}$ que molesta aos ditaum sistema descontinuo de ilcitudes. dores é, precis
seu poder".

"Pôsto em relação o princípio nullum crimen sine lege com esta concepç̃o - conclui o insigne mestre SOLER - aquêle esta core um rico, determinando uma exia adquire um sgnito a única exigência da lei prévia nova com respeito à lei antenor. A unica exigência da lei prévia não basta; esta lei deve reunir certos caracteres, deve ser concretamente definidora de uma ação, deve traçar uma figura encerradá em si mesma, em cuja virtude se conheça não sòmente qual é a conduta compreendida senão também qual é a não compre endida". (11)

Considera-se a proibicão da analogia um corolário do prin cípio nullum crimen sine praevia lege penali. Afirma-se, pois, que nuthum crínípio de reserva, que os sistemas juridico-penais que acolhem o principiochas ou la. são sistemas fechados, onde não se podem supor brechas ou lacunas.

Eis aí o momento culminante na problemática da analogia. Cumpre, então, distinguir. Há normas penais de três espécies: umas são as normas penais que definem o delito e criam 
o tipo específico a que deve corresponder determinada ação, tanto no seu momento subjetivo como objetivo. Ao lado das normas penais incriminadoras ou tipificadoras do delito, há as normas penais que se poderiam chamar de acessórias ou complementares. E há ainda uma terceira categoria de normas penais, sem o caráter de acessoriedade ou complementariedade: as normas que contemplam as causas que dirimem a culpabilidade ou excluem a injuridicidade da ação.

A proibição da analogia sòmente se refere às normas incriminadoras, pois estas são inextensíveis. Sòmente constitui delito a ação que corresponde exatamente ao esquema tipificador da norma. Mas, relativamente à aplicação das normas complementares ou das normas que isentam a culpabilidade ou a iliceidade, o processo analógico é perfeitamente legítimo, e funciona quer como revelacão da própria vontade da lei, inadequadamente expressa nos dispositivos componentes do sistema, quer como integração das lacunas que o próprio sistema apresenta. (12)

Em qualquer sistema de direito positivo, seria possível exemplificar. Tomemos o nosso como ilustração do problema.

No Código de 40, a analogia in bonam partem é, sem dúvida, larga e legitimamente utilizável. Quando se trata de reconhecer, ad instar de uma causa legal de exclusão da injuridicidade ou da culpabilidade, causa não prevista em lei, mas que se lhe equipare, atento o reconhecimento da liceidade da ação, nos limites em que foi exercida, ou reconhecido o motivo ético-jurídico que a inspira, o emprêgo da analogia pode constituir um recurso lícito de aplicação ou integração da lei penal. Do mesmo modo, no tocante às causas de extinção da punibilidade ou às que outorgarn condições beneficiadoras do agente.

(12) - A corrente prevalente na atual doutrina penal é no sentido do pensa-

mento expresso no texto.
Na moderna literatura penal estrangeira: A. SCHöNKE, Riv. Italiana
di Diritto Penale, ano 1949, n. 5 , págs. 514-15; HANS WELZEL, Dereeho Penal, traducão do alemão pelo dr. Fontán Balestra, B. Aires, 1956, pás. 28; G. MA TGro, Dir. Peenale, Bolonha, 1951, tomo I, pág. 132; SÍLVI SABATINI, Ist di Dir. Penale Catania, 1946, vol. vol. I, pág. 50;

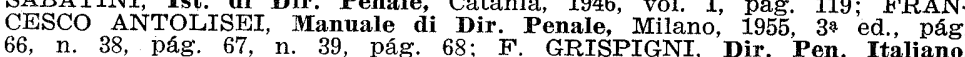
66, n. 38, pág. 67, n. 39, pág. 68; F. GRISPIGNI, Dir. Pen. Italiano,
Milano, 1950, vol. I, pág. 34; G. BETTIOL, Diritto Penale, Palermo
1950, pág. 94-95; PIERRE BOUZAT, Traité de Droit Penal, Paris, 1951, pág. 66. logicas, ainda que se amparem no critério da benignidade, in bonam partem
ou na pretendida indole comum e não excepcional de certas disposicõee legais. «A nuestro juicio, las eximentes, atenuantes, etc., son'leyes penale

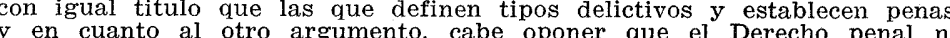
puede denominarse conjunto de leyes excepcionales, sino Derecho comín en su sentido amplio. Por tanto negamos que los preceptos de exención $\mathrm{y}$ atenuacion que pertenecen a la estera del Derecho penal, puedan ser objeto de procedimiento
1950 , tomo II, pág. 456 .
$\mathrm{Na}$ analogia intra legem, em se tratando de normas não incriminadoras, pode haver a ampliação da regra legal aos casos análogos, mesmo in malam partem. A fórmula com que foram definidas as agravantes do artigo $44 \mathrm{n}$. II letras $d$ e e, está a mostrar que o próprio legislador a ensejou.

Agrava a pena o fato de o agente ter cometido o crime à traição, de emboscada, ou mediante dissimulação, ou outro recurso que dificultou ou tornou impossível a defesa do ofendido. Ou se o crime foi cometido mediante veneno, fogo, explosivo, asfixia, tortura ou outro meio insidioso ou cruel ou de que podia resultar perigo comum. Ora, em tôdas essas hipóteses legais, o aplicador da lei penal deve valer-se da analogia para reconhecer circunstâncias não individualizadas pela lei, mas análogas às circunstâncias explicitamente previstas. (13)

Há a nosso ver outro exemplo ainda mais eloqüente, pelo relêvo que assume na nossa sistemática penal. $E^{\prime}$ o caso do artigo 42 que tão transcendente papel, como ainda veremos, desempenha no direito penal brasileiro. Êle também autoriza a aplicação analógica da lei. Quando o juíz, cumprindo a tarefa individualizadora da pena, atende à personalidade do agente, à sua vida pregressa, à intensidade do dolo ou grau da culpa, aos motivos, às circunstâncias e consequências do crime, o faz para reconhecer circunstâncias a favor ou contra o réu, circunstâncias que emergem da valoração do fato, em tôdas as dimensões a que aquêles elementos se reportam, ainda que não estejam definidas, como tais, pelo

Na literatura penal brasileira: COSTA E SILVA, Comentários ao Código em matéria penal in Aapêndice ao Código Penal, tomo II, São Paulo, 1938; JOSE' DUARTE, in Rev. Direito, vols. VI, págs. 87-102, VII, págs.
$70-87$, VIII, págs. 79-119; DEMOSTHENES MADUREIRA DE PINHO, analogia em matéria penal (cont. ao 10 Congresso Latino-americano de tem» e a lei de introdução ao Código Civil, sep. de Arquivos do Minist. da Justiça, 1944; NOE' AZEVEDO, As garantias da liberdade individual em face das novas tendências penais, S. Paulo, 1936; OSCAR STEVEN-
SON, Da Exelusão de Crime, S. Paulo, 1941, pág. 90; JOSE' FREDERICO MARQUES, Curso de Direito Penal, S. Paulo, 1954, vol. I, pág. 170; ANIBAL BRUNO, Direito Penal, Rio, 1956, tomo 19, pág. 218-19.
O eminente NELSON HUNGRIA entende que, fora do que êle chama interpretacão analógica ou analogia intra legem, não cabe o emprêgo da analogia, ainda que a servico do critério favorabilia amplianda (Op.
cit., tomo I, págs. $75-78$ ). Para êle interpretação analógica é cousa diversa da, analogia. Por isso, embora repelindo o procedimento analógico, HUNGRIA aceita a analogia intra legem ou interpretacão analógica. No isto é, aquela autorizada pela lei, quando sugere ao aplicador a extenda simples interpretacão

(13) - No brilhante acórdão da da $2^{n}$ Câmara Criminal do Egrégio Tribunal de
Justica dêste Estado e que teve, como relator, o eminente Des. CARLOS Justica dêste Fistado e que teve, como relator, o eminente Des. CARLOS
THOMPSON FLoRES, proferido no recurso-crime n. 2.274, de Bage, surpresa, dada a a inexistência do do elemento subjetivo, foi proclamada a possibilidade de seu jurídico reconhecimento, dentre as circunstâncias compreendidas pelo i
vol. 4, pág. 224-25). 
Código. Ora, na revelação dessas circunstâncias, o juíz procede, conduzido por um critério analógico, porque êle, de algum modo, tem em vista as circunstâncias legais de agravação ou de atenuação, para revelar aquelas que se lhe equiparem nos mesmos efeitos. Não está adstrito, como ressalta do artigo 42 , ao elenco legal. Mas as circunstâncias que êle explicita, no momento judicial da individualização da pena, hão de guardar certa analogia com as circunstâncias a que o legislador, no momento legislativo, conferiu os mesmos efeitos.

Em todos êsses casos, opera-se a integração do sistema legal, ainda que a analogia seja quase explìcitamente autorizada pelo legislador. Ainda porque a distinção entre analogia e interpretação analógica ou analogia intra legem não muda os têrmos do problema. $\mathrm{Na}$ interpretação realiza-se, de algum modo, a integração do sistema legal. A lei não pode abranger tôda a riqueza infinita do real. Só o êrro positivista acreditou que a lei pudesse exaurir o direito, concebendo sistemas jurídicos completos.

Tratando da Teoria Geral da Interpretação (14), em livro notável, aparecido na Itália, em 1955, EMILIO BETTI (15) escreve: "Um mais atento exame do fenômeno histórico e sociológico induz a reconhecer que não se trata de plenitude do sistema mas de coerência (a plenitude é uma meta ideal, jamais alcan cada); não se trata igualmente de universalidade, como se pretende, mas de uma totalidade espiritual, na qual é ínsita uma virtualidade que excede e ultrapassa as manifestações singulares e coloca o intérprete sob a exigência de uma integração e de um ulterior desdobramento".

A analogia é fonte do Direito penal, como o são, dentro de certos limites, o costume, (16) a equidade, os princípios gerais do direito.

A analogia serve ao princípio da individualização penal, em relação ao qual a equidade desempenha papel decisivo. E quando nos referimos ao princípio da individualizacão penal que a Constituição de 46 , no $\S 29$ do artigo 141 , elevou à dignidade de direito fundamental da pessoa, não o compreendemos apenas como um princípio regulador da pena, tal como sempre tem sido en tendido.

$\mathrm{O}$ princípio da individualização da pena, em sentido estrito se refere à qualidade e quantidade da pena. Mas, lato sensu, um princípio que comanda tôda a sistemática penal, informando não só a pena, mas também a teoria do delito.

A pena é tão só a consequêencia do delito. Não se pode

(14) - Teoria Generale della Interpretazione, Milano, 1955, dois tomos

(15) = Ob. cit., tomo II, pág. 864.
(16) - ADOLF SCHÖNKE, estudo cit. in loc. cit., pág. 513 individualizar a pena senão em função do delito. $E$, quando dizemos delito, estamos compreendendo, como é óbvio, o autor do delito. Dêste modo, é ao próprio delito, tanto em seu aspecto objetivo, como em seu aspecto subjetivo, que o princípio se refere.

Em nosso Sistema de Direito Penal Brasileiro (17) e sob a influência da teoria da tipicidade, escrevemos: "O delito está no mundo da cultura. O direito constitui um sistema de valores que se destinam a assegurar a realização do bem comum, concretizando, nas relações sociais, o valor supremo da justiça. O delito constitui justamente a negação de um valor. A norma penal que - protege, através da sanção, define o delito como a ação dotada de eficácia lesiva quanto ao valor a que o delito se opõe.

Assim, o problema se situa no plano das abstrações valoradorás e normativas. A noção jurídica do delito se opera na base de uma valoracão social e, em função dessa estimativa do bem jurídico, edita-se a norma, destinada a garantir a sua intangibilidade.

O delito não é qualquer ação, nem a ação pura e simples, mas a ação definida, determinada, típica - a ação que se dirige contra um bem juridicamente tutelado pela norma penal. $\mathrm{O}$ delito que é definido pela norma penal, situa-se, como noção jurídica, no mundo dos seres ideais. A entidade concreta do delito é um reflexo de uma entidade ideal. $\mathrm{O}$ delito se realiza - conclúamos - na medida em que concretiza aquêle modêlo ou arquétipo ideal".

Não significam os conceitos expendidos sôbre a noção do delito a resultante de uma posição extremamente idealista e apriorista, no campo da ontologia e da teoria do conhecimento. A necessidade da abstração do delito na norma penal é um imperativo de segurança.

A teoria em tôrno do delito-tipo necessita, contudo, sofrer o contraste do princípio de individualização.

Há na teoria da tipicidade uma categoria apriorista que necessita sofrer a relativacão do concreto e do individual.

Deve operar-se uma tensão recíproca entre a abstração da lei e a concrecão do real. Os elementos do delito devem realizar formas específicas de injuridicidade e de culpabilidade, segundo o tipo descrito na lei penal, mas a injuridicidade e a culpabilidade inserem-se na acão concreta do agente. Assim o seu sentido pleno sòmente poderá ser alcançado através da valoração de múltiplos fatores: a personalidade do agente, o motivo, as circunstâncias, o complexo psíquico-situacional que o determina e explica.

E' ao atendimento dessas exigências de concreção que o princípio serve.

(17) - Op. cit., Rio, 1957, pág. 162 
A individualização se realiza desde a fase legislativa, quando as diversas figuras delituosas são determinadas e definidas através de uma captação que o legislador opera sôbre o fluir da realidade humana e social.

Depois são as circunstâncias modalizadoras do fato delituoso. As agravantes e as atenuantes servem ao princípio individualizador, não sòmente com reflexos sôbre a pena, mas sôbre o próprio delito. $\mathrm{E}$, por último, nos sistemas como o acolhido pelo diploma penal brasileiro, a individualização culmina quando o juíz tem a faculdade de atender e conferir relevância a elementos peculiares a cada fato concreto.

A fixação da pena no direito brasileiro pressupõe um trabalho preliminar de valoração integral do fato. Tôdas as perspectivas objetivas e subjetivas que êle comporta, são apreciadas e interpretadas pelo juíz. A ação e o seu finalismo, a injuridicidade, a culpabilidade são fixadas não só em função da tipicidade: esta representa o crivo através do qual o juíz faz passar o fato em sua palpitante realidade e em tôda a riqueza de sua concreção individual.

O esquema da tipificação não deve ser um leito de Procusto.

Há algo que sempre escapa à previsão do legislador.

MIGUEL REALE, (18) o eminente professor de Filosofia do Direito da Faculdade de São Paulo, ainda recentemente, entre nós, advertiu da Crise do Normativismo Jurídico e da Exigência de uma Normatividade Concreta.

"Na concepção do normativismo abstrato, a validade da regra é per se stante, de maneira que, por mera inferência lógica, a ela devem se conformar dadas realidades particulares: a norma como tal é o têrmo lógico conclusivo de um processo em si mesmo cerrado e lògicamente imutável, até e enquanto outro enunciado lógico não o venha substituir, pela via normativa da revogação formal. Emanada a norma e enquanto esta se mantem em vigência, o que pode ocorrer são fatos e experiências axiológicas correspondentes ou não ao esquema previsto: a juridicidade ou não decorrerá, por isto, do ajuste ou do desajuste entre o evento concreto e o enunciado da regra in abstracto.

Em uma concepção de "normativismo concreto", ao contrário, exatamente porque a mesma não é uma simples estrutura lógicoformal, ou um modêlo, mas prevê e envolve necessàriamente o momento futuro de uma ação concreta do homem, é necessário distinguir:
1" - entre o "juízo-lógico", (o suporte ideal mediante o qual se expressa algo) e o valor expresso pelo juízo: suporte lógico e valor formam, em seu conjunto unitário, a norma jurídica, que, dêsse modo, não pode ser reduzida a um de seus dois elementos componentes;

$2^{\circ}$ - entre a validade da norma jurídica, examinada em si mesma - como, digamos assim, um anel destacado de uma corrente, ou conta desligada do rosário - $f$ a sua validade inserida no complexo do sistema ou do ordenamento".

Essa tensão entre a realidade e a norma realca a importância da interpretacão, a riqueza da analogia, a necessidade do princípio individualizador.

O Direito Penal é, consoante a lição de SOLER, um sistema descontínuo de ilicitudes. Deve constituir um sistema comandado pelo princípio de reserva, no que tange à matéria de incriminaçóes e sanções. Mas, disciplina profundamente humana e social de quantas mais o sejam, o direito penal é eminentemente permeáve a tôdas as exigências valorativas que o clima cultural e espiritua de cada época erige e compõe. A noção do delito não é insensível aos imperativos dessa normatividade concreta. Se variam os critérios estimativos quanto aos valores que o delito ofende, como não variar também a própria noção do delito e os elementos que a compõem? Estado,

O princípio de reserva é uma garantia contra o arbítrio do

E', ao mesmo tempo, uma garantia política e um princípio jurídico.

A doutrina da tipicidade o enriqueceu. A concepção de um normativismo concreto a que aludem as modernas correntes da filosofia jurídica, limita a ortodoxia com que êle foi formulado, para se opor às épocas de opressão e de obscurantismo.

SOLER (19) salienta o sentido oposto em que se movem em sua moderna evolução os conceitos de contrato e de delito. $\mathrm{Na}$ teoria clássica, fundada no princípio nullum crimen sine lege, o conceito do delito deve construir-se como típico, porque não há nenhum delito genérico que desempenhe a função de comun denominador delitual: há tantos delitos como tipos. Exatamente, ao revés do que ocorre com a teoria do contrato, na qual o contrato inominado cumpre aquela função legalizadora dos convênio atípicos, não há delito inominado. $\mathrm{E}$ assim explica o fenômeno: 
Trata-se de uma manifestação do crescimento do Estado. O direito contratual regula fundamentalmente a atividade dos cidadãos, $\mathrm{e}$, por isso, verifica-se a tendência a restringíla, a lo penal, a criação de figuras delituosas, regula a atividade punitiva Estado. Em consequencia tende-se a ampliá-la, a despojá-la de entraves, a conferir-lhe mais livre jôgo.

O princípio de reserva deve continuar a proibir a analogia incriminadora. Feita esta restrição, garantidora da a analogia da dignidade da pessoa, a analogia constitui fonte do direito penal e, associada à equidade, constitui norma individualizadora, descobrindo as relações entre a abstração da lei e a concreção variável e específica do real.

\title{
ECONOMIA DIRIGIDA E DIREITO COMERCIAL *
}

\author{
HERNANI ESTRELLA
}

Catedrático de Direito Comercial.

1. - A economia liberal no Brasil. 2. - o comércio exterior brasileiro. 3 . - 0 mercado de consumo interno. 4. - As idéias de livre iniciativa e livre emprêsa na contextura do nosso direito comercial. 5. - Valorização artificial. 6. - Crescente intervencionismo econômico. 7. - Produção e circulação controladas. 8. - Estado empresário e competidor privilegiado. 9. - Intervenção corretiva ou supletiva e não supressiva. 10. - Inaptidão congênita do poder público para ser empresário. 11. - Posição do direito comercial face à economia dirigida. 12 . Comercialização do direito público. 13. - Submissão do Estado comerciante ao império do direito comercial.

1. - O Brasil se fez independente e viveu a maior parte de sua existência, sob o signo da chamada economia liberal. No largo período de mais de um século, que vai da Independência ao fim da primeira República, ou, mais precisamente, da Constituição de 1824 à de 1891, abrogada pelo golpe de estado de 1930, foram completamente livres em nosso país tôdas as atividades econômicas. Exceção feita da navegação de cabotagem, reservada aos nacionais por motivos óbvios e salvo, também, medidas de caráter aduaneiro, tendentes a estimular a indústria incipiente e propiciar renda ao tesouro, a posição do Estado era de vigilância e tutela.

Tôdas as formas de produção eram franqueadas, indistintamente, a nacionais e estrangeiros. $\mathrm{O}$ capital alienígena podia en trar livremente no país, aqui aplicar-se a qualqưer gênero de in- 